536. 423. 1:536. 252

\title{
Heat Transfer in Surface Boiling under Free Convection*
}

\author{
By Kaneyasu NishikAwA** and Hisao KusudA***
}

Through an experiment of nucleate boiling under free convection in subcooled water, we came to the following conclusions :

(1) The effective stirring length of bubbles in surface boiling is reasonably estimated to be one-third of their condensing height which is determined identically with the dgree of subcooling of bulk water.

(2) Correlation of heat transfer in surface boiling using $\Delta \theta_{s}$ instead of $\Delta \theta$ corresponds to the replacing of $H_{e}$ by $H_{e s}$, where

$\Delta \theta_{s}$ : temperature difference between heating surface and saturated liquid,

$\Delta \theta:$ temperature difference between heating surface and bulk liquid,

$H_{e}$ : effective stirring length of bubbles in saturated boiling,

$H_{e s}$ : effective stirring length of bubbles in surface boiling.

From these conclusions, we derived an extension of author's correlating equation of nucleate boiling heat transfer, and confirmed that it fairly agreed with the experimental results in surface boiling.

\section{Introduction}

What characterizes boiling heat transfer is that heat is transferred extremely well owing to the disturbance caused to bulk liquid by bubbles generated.

In surface boiling, it is generally believed, the bubbles generated induce a disturbance again when they condense and collapse due to the low temperature of the bulk liquid and thereby heat transfer becomes better than in saturated boiling. However, experiments mostly made on surface boiling have been hitherto carried out under forced convection, where heat transfer is subject to combined effects, such as depending only on boiling or only on convection. It seems to be too hasty to conclude that surface boiling gives better heat transfer than saturated boiling, simply from the results of the experiments made so far under forced convection. According to the results of investigation made by one of the authors on the effect of heat loss from the side wall of a vessel when heat transfer coefficient of the boiling under free convection was

* Received 2nd February, 1963.

** Professor, Faculty of Engineering, Kyushu University, Fukuoka.

*** Assistant-Professor, Training Institute for Engineering Teachers, Kyushu University. measured $^{(1)}$, the heat loss was very large, and when bulk liquid was cooler than its saturation temperature, the heat transfer coefficient obtained was smaller than that in the case of saturation temperature.

As shown in Fig. 1, since bubble generation and collapse in the case of surface boiling under free convection seriously influence heat transfer just as they do in saturated boiling, it is necessary to clarify the mechanism of bubble generation and collapse before anything.

Since surface boiling first attracted general attention as the means of obtaining high heat flux with the recent progress of jet engines and atomic

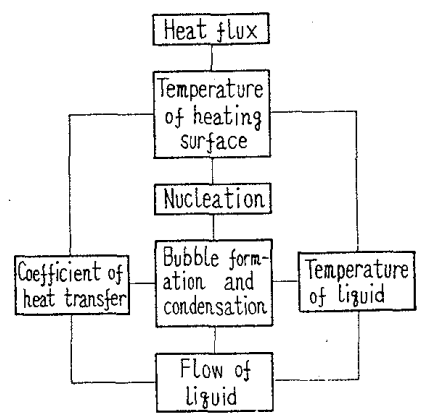

Fig. 1 Relation between coefficient of heat transfer in surface boiling and its principal factors 
power plants, a number of reports have been written by many investigators who measured the coefficient of heat transfer under special conditions ${ }^{(2)}$. The results show differences, leaving problems in several points.

Recently many experimental studies on bubble generation and collapse itself have been reported, but there is hardly found any attempt to correlate bubble generation-collapse with heat transfer of the system.

This paper gives the results of an experiment carried out by using apparatus for free convection considering chiefly the relation between the heat transfer of system and the bubble generation-collapse which is the dominating factor in the surface boiling.

\section{Method of experiment}

A schematic view of the experimental apparatus is shown in Fig. 2. The heating surface was a circular brass plate of $100 \mathrm{~mm}$ in diameter and $5 \mathrm{~mm}$ thick and the construction of the heater was nearly the same as the horizontal heating surface once used by Jakob ${ }^{(3)}$, but German silver was used both on the side and the bottom of the heater with an



a: heating surface

$\mathrm{b}$ : electric heater for heating surface

c: glass wool

$d$ : inner vessel (beaker)

e: lid for inner vessel

$f_{1}, f_{2}, f_{3}$ : thermocouples for measuring the temperature of heating surface

$g$ : thermocouples for measuring the temperature of liquid

$\mathrm{h}$ : outlet of vapor

: outer vessel (water jacket)

$j$ : cast-in heater for heating jacket water

: stirring propeller

: thermometer for jacket water

. thermal insulator

n: glass window for peep

$o, p$ : leading wire for electric heaters

Fig. 2 Experimental apparatus air room attached to the bottom in order to minimize heat loss. The vessel (inner vessel) in which the heating surface was set was a beaker $175 \mathrm{~mm}$ in diameter and $270 \mathrm{~mm}$ in high. This beaker was tightly covered with a rubber plate wrapped with vinyl cloth. On this rubber lid, several ports were bored for outlets of thermocouples and lead wires to nichrome coil of the heater. This inner vessel filled with distilled water up to the level of $100 \mathrm{~mm}$ high above the heating surface was set in the large vessel (outer vessel) filled with jacket water as shown in Fig. 2. Cast-in heaters and stirring propellers were attached to this outer vessel in order to control and make the temperature of jacket water uniform. The degree of subcooling of test liquid in the inner vessel was controlled by changing the temperature of jacket water. The outer vessel had parallel glass-windows on both opposite sides for internal observation.

The temperature of heating surface was sought for by correcting the value that had been obtained by means of thermocouples inserted into the holes which were bored radially in the middle of thickness of the heating plate to the depth of 10,30 and 50 $\mathrm{mm}$ respectively from the end of the plate. The distribution of temperature of boiling liquid was measured by shifting vertically the movable group of thermocouples, middle element of which was moved along the central axis of heating surface and the others along each axis parallel to the central one at distances of $10,20,30,40,50$ and $60 \mathrm{~mm}$ respectively from the center of heating surface. For calculation of the coefficient of heat transfer, according to the reason mentioned later, we used the temperature at the center of the plate as the temperature of heating surface and the temperature of liquid at the point of $40 \mathrm{~mm}$ above the heating surface and $10 \mathrm{~mm}$ outside from the end of heating plate as the temperature of bulk liquid. In addition, we observed the number of vapor columns and their condensing height above the heating surface by vision and measured the diameter of bubble just leaving the heating surface and the frequency of bubble formation by a specially designed optical method ${ }^{(4)}$.

Experiment was carried out at a constant liquid level of $100 \mathrm{~mm}$ above the heating surface and at several temperatures of jacket water between $70^{\circ} \mathrm{C}$ and $100^{\circ} \mathrm{C}$, and the range of heat flux used in this experiment was 21900 to $71175 \mathrm{kcal} / \mathrm{m}^{2} \mathrm{hr}$.

\section{Results of experiment and discussion}

3.1 Aspect of bubble formation and collapse In surface boiling, bubbles once formed on the 
heating surface condense and collapse in subcooled liquid because the temperature of liquid is below the saturation temperature although the temperature of heating surface is high enough to generate bubbles. Accordingly, no effective vapor generation occurs.

Photographs of outside views of boiling are shown in Fig. 3 and the corresponding temperature profiles of liquid in Fig. 4. Every figure is for a constant heat flux $22460 \mathrm{kcal} / \mathrm{m}^{2} \mathrm{hr}$ and $\theta_{m}$ (temperature of jacket water) of 98,94 and $88^{\circ} \mathrm{C}$ respectively. At the temperature $\theta_{m}=98^{\circ} \mathrm{C}$, the aspect of boiling is, in appearance, not different from that in saturated boiling, namely, bubbles formed rise to the free liquid

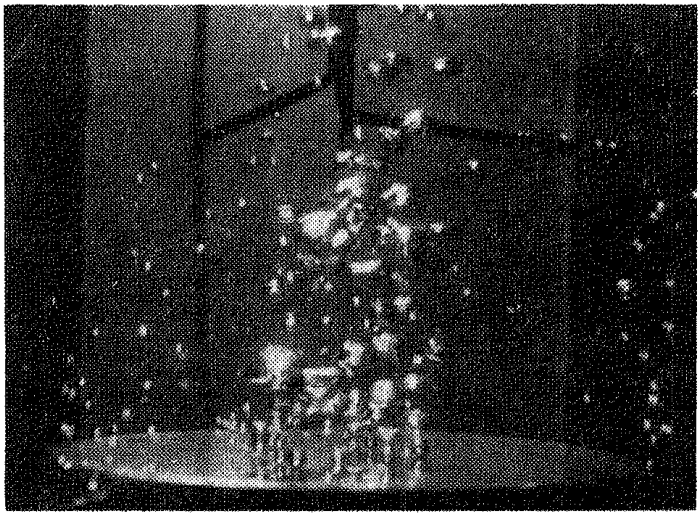

$\theta_{m}=98^{\circ} \mathrm{C}, \quad h=100 \mathrm{~mm}$

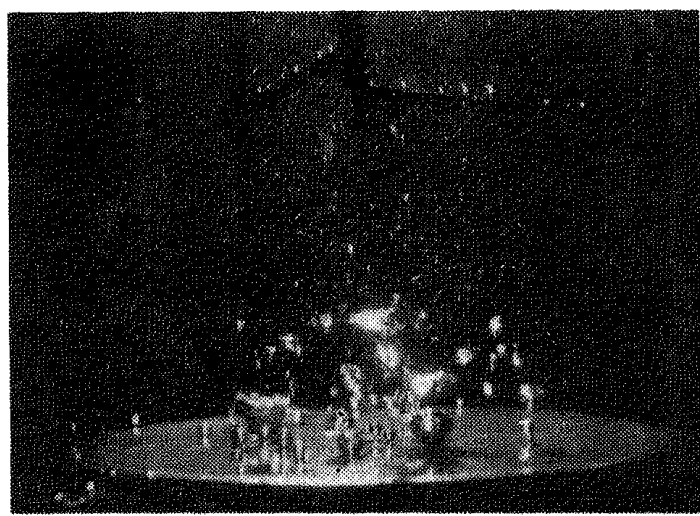

$\theta_{m}=94^{\circ} \mathrm{C}, \quad h=20 \mathrm{~mm}$

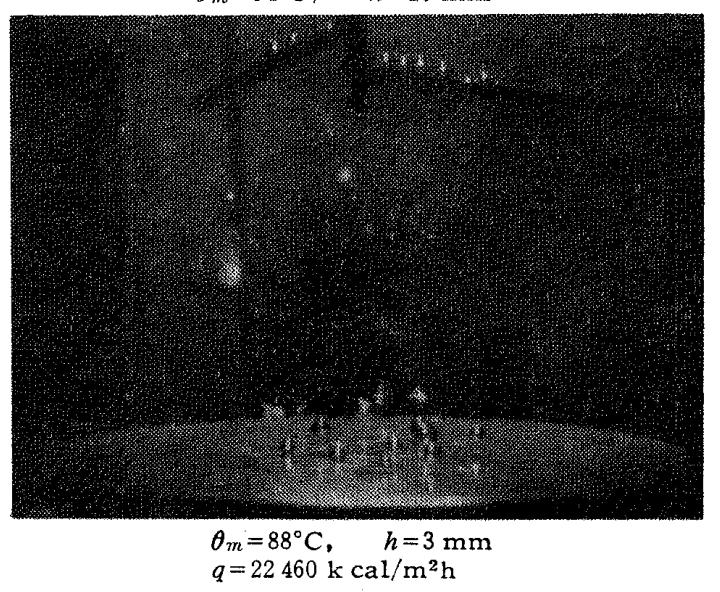

Fig. 3 Photographs of outside view of boiling aspects surface and the temperature of liquid $\theta_{w}$ above heating surface is almost uniformly $100^{\circ} \mathrm{C}$. At the temperature $\theta_{m}=94^{\circ} \mathrm{C}$, bubbles generated rise only a short distance from the heating surface and after a while condense, then, they tend to break up into very small bubbles and in such case, the temperature of liquid is lower than $100^{\circ} \mathrm{C}$ at a distance of only a few millimeters from the heating surface and, in addition, existence of temperature gradient in radial direction is observed. Furthermore, at $\theta_{m}=88^{\circ} \mathrm{C}$, bubbles formed hardly rise any distance but immediately condense and a temperature gradient appears not only in radial direction but also in axial direction; specially, it seems to be extraordinary along the vertical axis at a distance of $5 \mathrm{~cm}$ from the center of heating surface, that is, in the cylindrical surface including the end of heating surface. In this cylindrical surface, liquid temperature gradually falls with an increasing distance downwards from free liquid surface, and remarkably drops near the level of heating surface and next it abruptly rises. This tendency becomes more remarkable with an increasing amount of subcooling $\Delta \theta_{\text {sub }}=\theta_{s}-\theta_{w}$. This fact seems to show the existence of not only a downward flow but also an upward flow in the cylindrical surface including the end of heating surface. Accordingly, it appears that, detailed measurement of distribution of temperature of liquid and observation about the condition of flow are necessary for study on surface boiling. Above-mentioned observations are for a heat flux of $22460 \mathrm{kcal} / \mathrm{m}^{2} \mathrm{hr}$ and their tendency are quite the same with different heat fluxes, too.

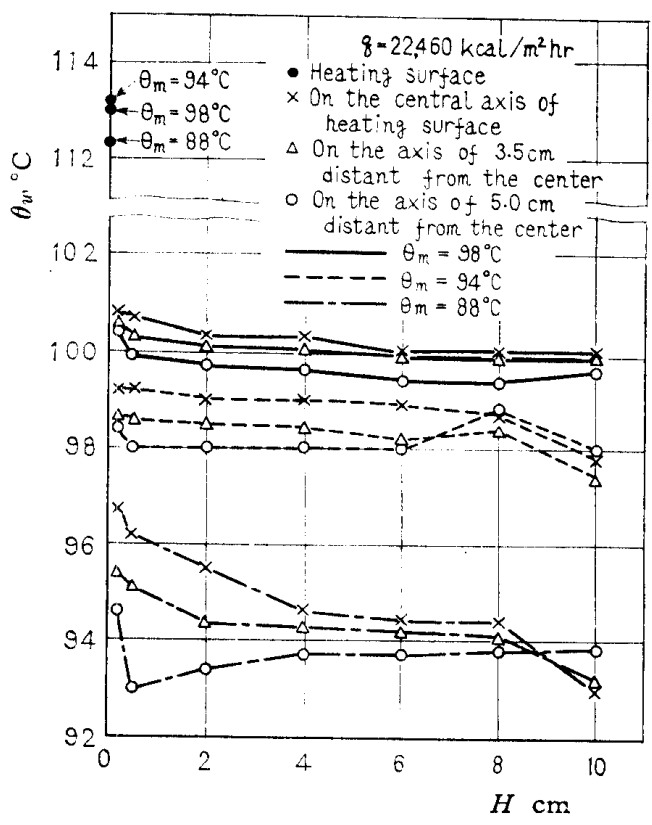

Fig. 4 Temperature distribution of liquid in inner vessel 
Some of photographs which continuously recorded images of bubbles just leaving the heating surface one after another are shown in Fig. 5 . It appears that for the same heat flux, though the number of vapor columns varies with the degree of subcooling there seems not to be any remarkable change in bubble diameter and frequency of bubble formation.

In Fig. 6 the relation between the amount of subcooling and maximum diameter of bubble attaching to the heating surface being measured from photographs in Fig. 5 is illustrated. As it is clear from this figure, there is no remarkable change of

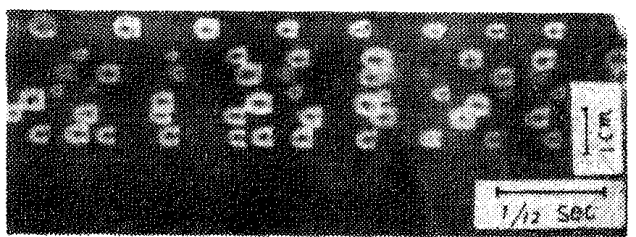

$q=21900 \mathrm{kcall} / \mathrm{m}^{2} \mathrm{hr}, \quad \theta_{\mathrm{sub}}=2.24^{\circ} \mathrm{C}$

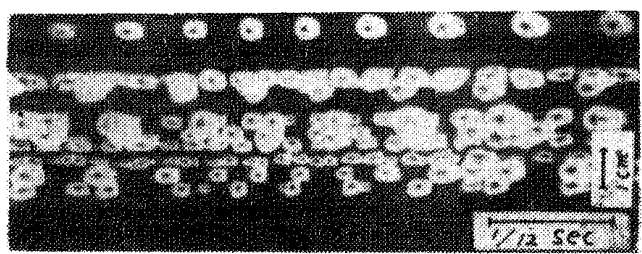

$q=38325 \mathrm{kca} 1 / \mathrm{m}^{2} \mathrm{hr}, \quad \Delta \theta_{\mathrm{sub}}=4.35^{\circ} \mathrm{C}$

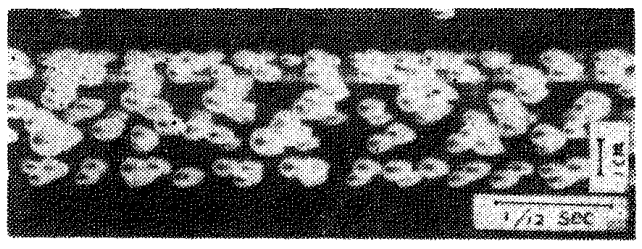

$q=43800 \mathrm{kcal} / \mathrm{m}^{2} \mathrm{hr}, \quad \theta_{\mathrm{sub}}=1.56^{\circ} \mathrm{C}$

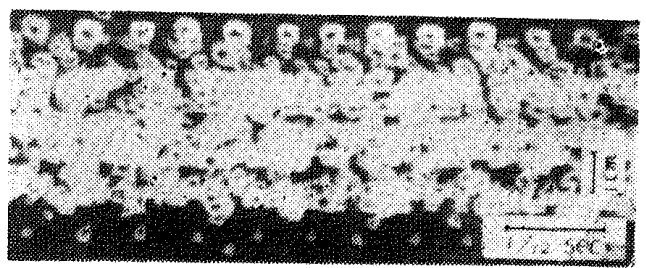

$q=54750 \mathrm{kcal} / \mathrm{m}^{2} \mathrm{hr}$,

$\Delta \theta \mathrm{sub}=2.34^{\circ} \mathrm{C}$

Fig. 5 Photographs of bubbles just leaving the heating surface

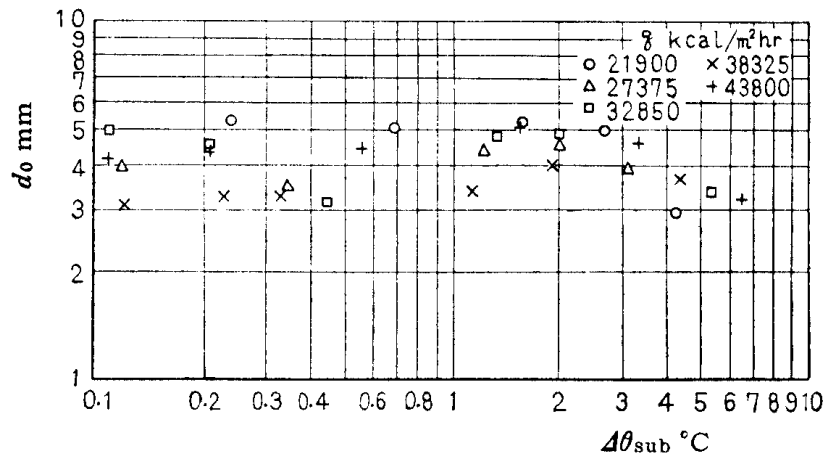

Fig. 6 Diameter of bubbles just leaving the heating surface for various degrees of subcooling $d_{0}$ due to $\Delta \theta_{\mathrm{sub}}$ but $d_{0}$ slightly decreases in the range of $\Delta \theta_{\mathrm{sub}}>4^{\circ} \mathrm{C}$ and it seems to be independent of heat flux. With reference to the frequency of bubble formation $f$, though the scattering of data is larger than in the case of $d_{0}$, there is not any systematic variation due to the degree of subcooling and heat flux. Accordingly, as shown in Fig. 7, the values of product $d_{0} f$ seem to be nearly constant independently of the amount of subcooling and heat flux and their absolute values coincide with those in saturated boiling $\left(d_{0} f=400 \mathrm{~m} / \mathrm{hr}\right)$. In other words, it is concluded that in the range of this experiment,

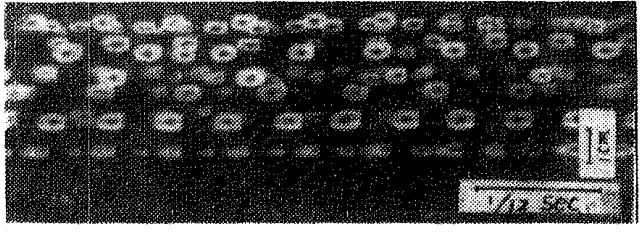

$q=32850 \mathrm{kcal} / \mathrm{m}^{2} \mathrm{hr}, \quad \Delta \theta_{\mathrm{sub}}=5.36^{\circ} \mathrm{C}$

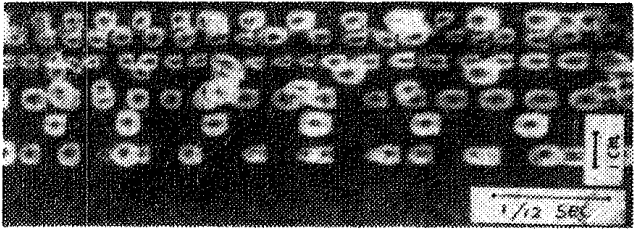

$q=32850 \mathrm{kcal} / \mathrm{m}^{2} \mathrm{hr}, \quad \Delta 9_{\mathrm{sub}}=1.34^{\circ} \mathrm{C}$

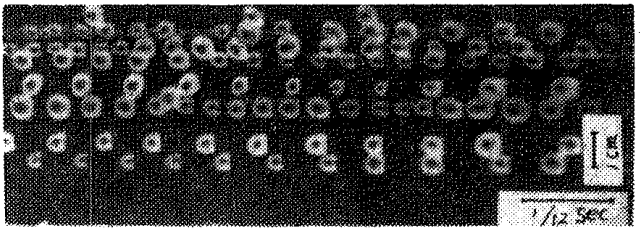

$q=32850 \mathrm{kcal} / \mathrm{m}^{2} \mathrm{hr}, \quad \Delta \theta_{\mathrm{sub}}=0.21^{\circ} \mathrm{C}$

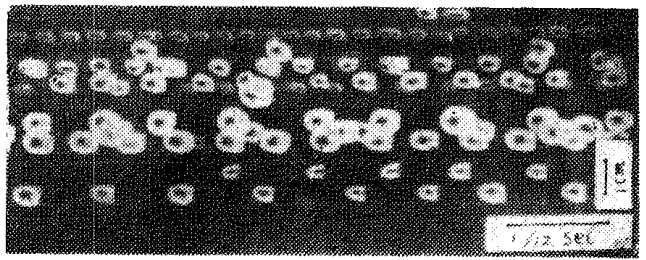

$q=32850 \mathrm{kcal} / \mathrm{m}^{2} \mathrm{hr}, \quad \Delta \theta_{\mathrm{sub}}=0^{\circ} \mathrm{C}$

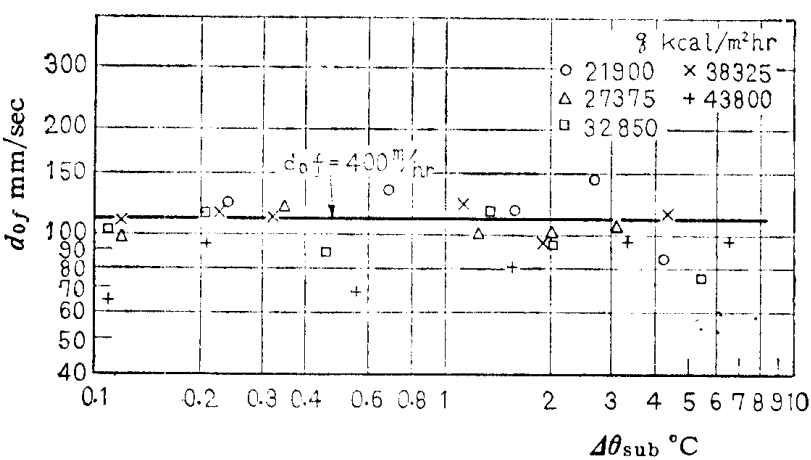

Fig. 7 Product of bubble diameter and fre quency of formation related to degree of subcooling 
there is no different aspect in bubble formation between saturated boiling and surface boiling.

Now, the condensing height of bubbles, i.e., the distance from heating surface travelled by bubbles during their life time of course varies according to the temperature of jacket water $\theta_{m}$.

However, the scattering of experimental data is remarkable when $h$ is correlated to $\theta_{m}$. Then, if $h$ is plotted against $\Delta \theta_{\mathrm{sub}}$, the result will be as seen in Fig. 8, and an identical relation between $h$ and $\Delta \theta_{\text {sub }}$ is found independently of heat flux, in the range of this experiment. In the above-mentioned figures, we did not take the total mean temperature of bulk liquid but, as aforementioned, the temperature at the point $40 \mathrm{~mm}$ high above and $10 \mathrm{~mm}$ distant outwards from the end of heating surface as the temperature of liquid $\theta_{w}$. The reason for this choice is that axial distribution of temperature at this point is uniform, and the liquid is considered to have the most intense upwards flow along the central axis of heating surface and arriving at free liquid surface, it flows down along the inside wall of inner vessel and finally, in the plane of heating surface, it radially flows in towards the center, therefore, it seems to be proper to take this temperature as standard temperature of liquid referring to heat transfer. In this report, this temperature is taken as standard temperature in the following calculation of coefficient of heat transfer.

In Fig. 8 , the maximum of condensing height is $100 \mathrm{~mm}$ because our experiment has been carried out at a constant level of $100 \mathrm{~mm}$ and, as mentioned later, it has no significance to consider any level higher than $100 \mathrm{~mm}$ with respect to heat transfer. Condensing height $h$ is not considered to decrease infinitely with an increase of subcooling because there must be a minimum size of bubble diameter for bubble formation, that is, critical radius and, theoretically, there should not exist any condensing

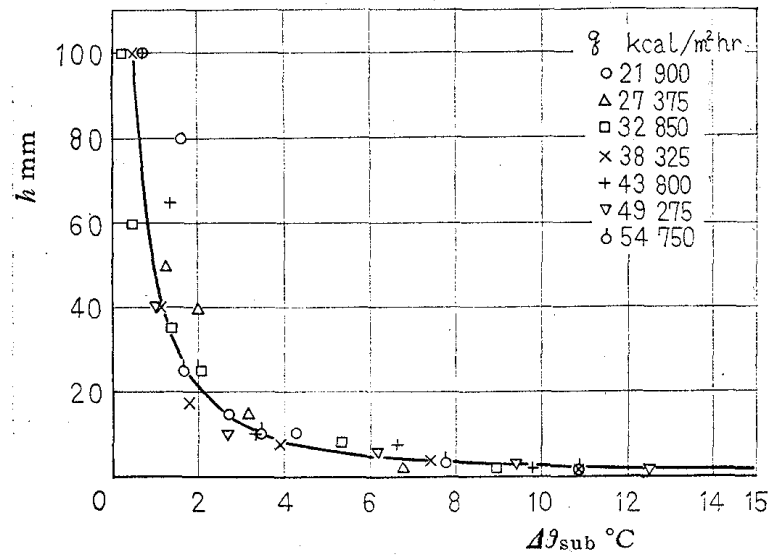

Fig. 8 Relation between condensing height of bubbles and degree of subcooling height smaller than critical radius.

Presently, at least, any bubble smaller than 1 $\mathrm{mm}$ in diameter hardly seems to contribute to the stirring of liquid.

In accordance with these two results of this experiment, the difference of liquid stirring effect by bubbles between surface boiling and saturated boiling should be properly attributed chiefly to the difference of effective stirring length of bubbles.

3.2 Coefficient of heat transfer In Fig. 9 the coefficient of heat transfer $\alpha$ is plotted against the degree of subcooling $\Delta \theta_{\text {sub }}$ for each value of heat flux. Initially, $\alpha$ rapidly decreases with an increasing $\Delta \theta_{\mathrm{sub}}$, then its rate of decrease becomes relatively small for $\Delta \theta_{\text {sub }}$ larger than a certain value. The point where the gradient of the curve of $\alpha$ versus $\Delta \theta_{\text {sub }}$ abruptly changes corresponds to the starting point of boiling.

It is the well known fact that the coefficient of boiling heat transfer is dominated by the stirring effect of bubbles. According to the theoretical formula derived by one of the authors, the stirring effect of bubbles is a function of $n d_{0}^{3} f H_{e s}$.

Now, in surface boiling, the stirring effect of bubbles decreases not only because of the increasing distance of rising bubble from the heating surface, but also owing to the decreasing diameter of rising

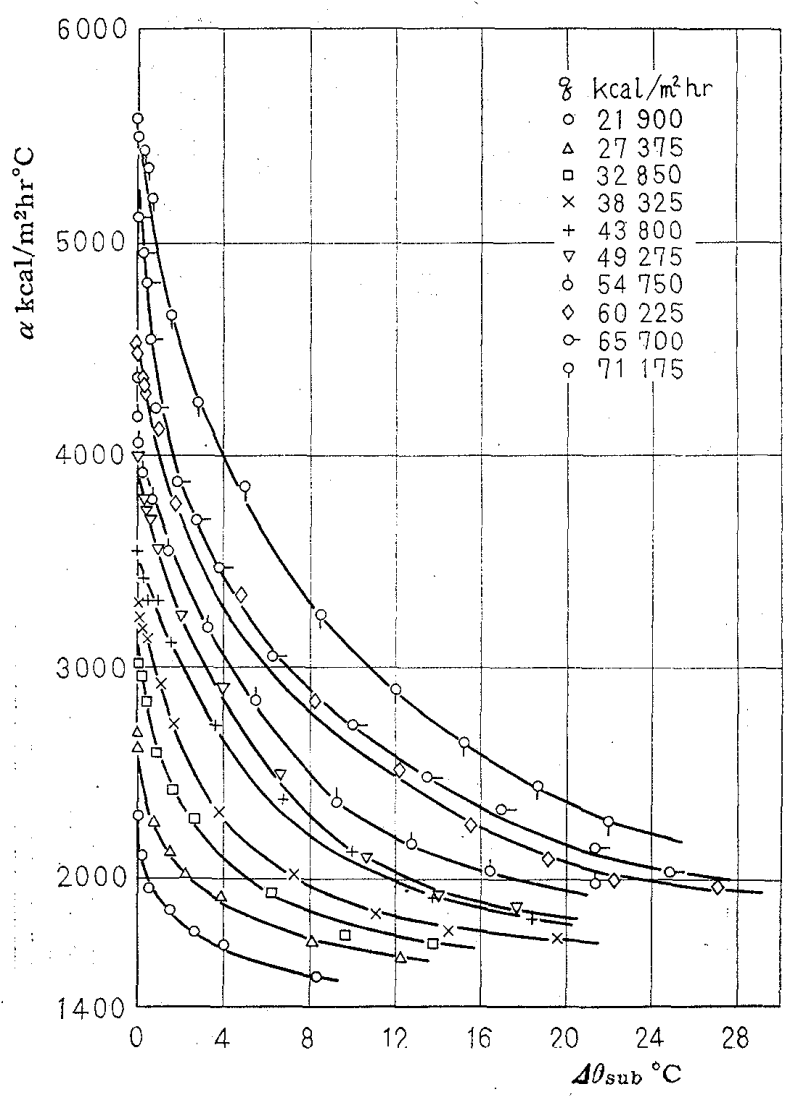

Fig. 9 Correlation of heat transfer coefficient with the degree of subcooling 
and condensing bubble. Then, for such bubble which condenses as it rises, we replaced a vapor column at a nucleating site by a cone and considered the height of cylinder of the same volume as this cone as the effective stirring length of bubbles in surface boiling. In other words, one third of the condensing height of bubbles was considered to be the effective stirring length of bubbles.

Since the effective stirring length in saturated boiling is $30 \mathrm{~mm}, H_{e s}$ must be taken as $30 \mathrm{~mm}$ even if it is larger than $30 \mathrm{~mm}$.

From such consideration above-mentioned, and assuming $H_{e s}=(1 / 3) h$ in surface boiling, the relation between $\alpha$ and $n d_{0}^{3} f H_{e s}$ was plotted in Fig. 10 using $H_{e s}$ which was determined according to Fig. 3 for given amount of subcooling.

Thus all points on several curves in Fig. 9 were arranged on one curve as shown in Fig. 10. In Fig. 10 , the region of small value of $n d_{0}{ }^{3} f H_{e s}$ is the domain where the value of free convectional driving force is the same order as that of driving force due to boiling and in the region where the effect of boiling dominates, we obtain the next relation;

\section{$\alpha \propto\left(n d_{0}^{3} f H_{e s}\right)^{1 / 3}$ \\ 4. Correlation of coefficient of heat transfer}

One of the authors had logically derived a correlating equation of heat transfer in saturated boiling ${ }^{(5)}$. This equation written for atmospheric pressure is as follows :

$$
Y=6.35 X^{2 / 3}
$$

where

$$
\begin{aligned}
& X \equiv\left[\frac{1}{M^{2} P} \frac{c_{p} \gamma^{\prime 2}}{\lambda \sigma r \gamma^{\prime \prime}}\right]^{1 / 2} R^{3 / 2} q \\
& Y \equiv \alpha R / \lambda \ldots \ldots \ldots \ldots \ldots \ldots \ldots \ldots \ldots \ldots \ldots \ldots \ldots \ldots
\end{aligned}
$$

On the other hand, it is well known that, when heat flux $q$ is plotted against temperature difference between heating surface and liquid $\Delta \theta$, experimental data separate from each other according to temperature of liquid as a parameter, but if $q$ is plotted against temperature differeace between heating

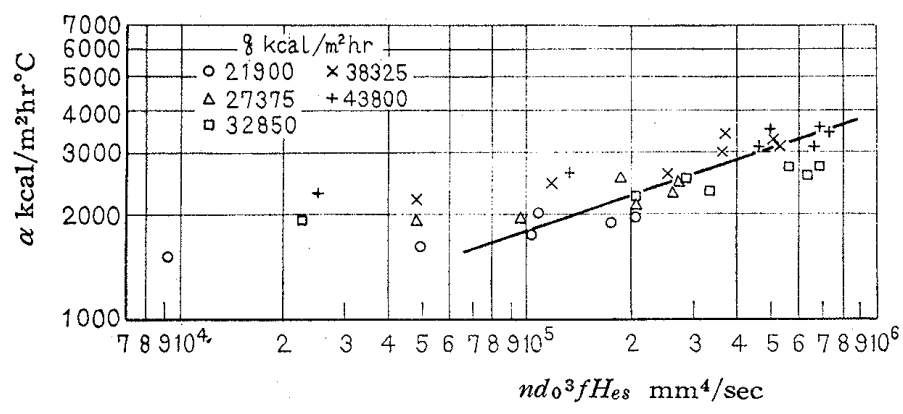

Fig.10 Correlation of coefficient of heat transfer by stirring effect bubbles surface and saturated liquid $\Delta \theta_{s}$ experimental data are brought together on one curve, and $q$ and $\Delta \theta_{s}$ are in the same relation as that between $q$ and $\Delta \theta$ in saturated boiling ${ }^{(6)}$. Then, Eq. (1) is rewritten as follows :

$$
\alpha=A q^{2 / 3}
$$

where

$$
A \equiv 6.35 \lambda\left[\frac{1}{M^{2} P} \frac{c_{p} \gamma^{\prime 2}}{\lambda \sigma r \gamma^{\prime \prime}}\right]^{1 / 3}
$$

Transforming Eq. (4) into the relation between $q$ and $\Delta \theta$ yields :

$q \equiv A^{3} \Delta \theta^{3}$

Replacing $\Delta \theta$ in Eq. (6) with $\Delta \theta_{s}$, a correlating equation of surface boiling is obtained as follws :

$$
\begin{aligned}
& q=A^{3} \Delta \theta_{s}{ }^{3}=A^{3}\left(\Delta \theta_{s} / \Delta \theta\right)^{3}(q / \alpha)^{3} \\
& \therefore \quad \alpha=A\left(\Delta \theta_{s} / \Delta \theta\right) q^{2 / 3} \\
& \therefore \quad Y=6.35(\bar{X})^{2 / 3} \ldots \ldots \ldots \ldots \ldots \ldots
\end{aligned}
$$

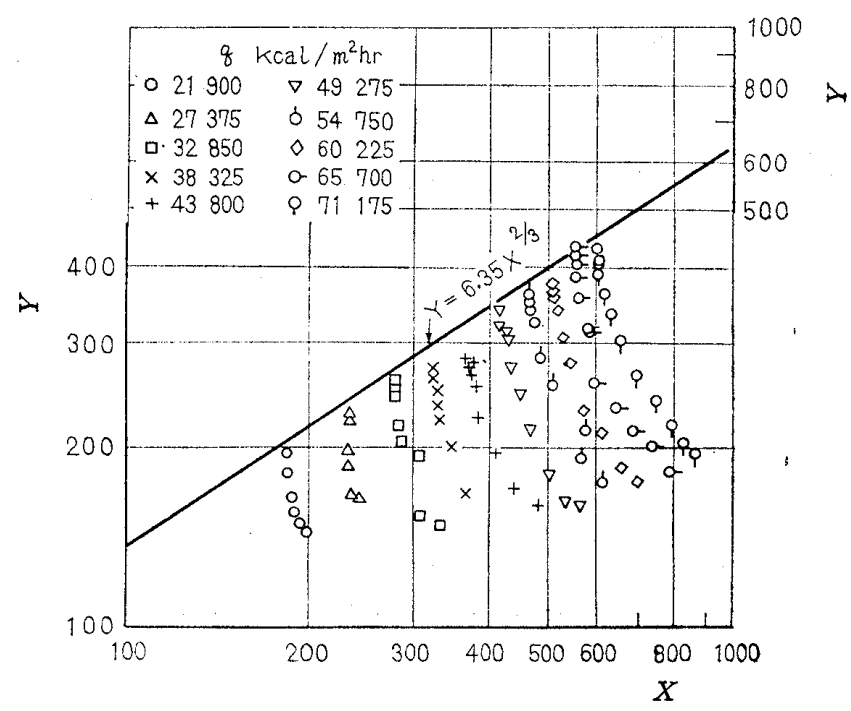

Fig.11 Correlation of heat transfer with $Y$ versus $X$

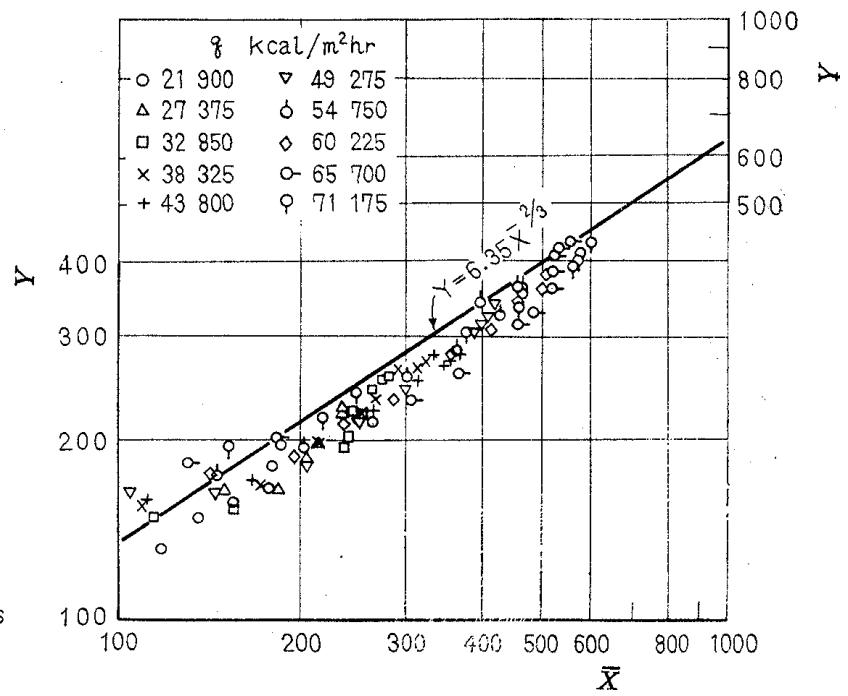

Fig.12 Correlation of heat transfer with $Y$ versus $\bar{X}$ 
where

$\bar{X} \equiv X\left(\Delta \theta_{s} / \Delta \theta\right)^{3 / 2}$

Hereby, it has been clarified that, Eq. (8) obtained by means of replacing $q$ in Eq. (1) with $q\left(\Delta \theta_{s}\right)$ $\Delta \theta)^{3 / 2}$ can be used in surface boiling.

Experimental data correlated by $Y$ versus $X$ are shown in Fig. 11 and by $Y$ versus $\bar{X}$ in Fig. 12 .

As seen in these figures, at least in the range of this experiment, the above-mentioned method of correlating the heat transfer in surface boiling seems to be valid. For instance, let us consider about Levy's correlating equation ${ }^{(7)}$ from this viewpoint. Levy proposed the following correlating equation for saturated boiling :

$$
q=\frac{J \lambda c_{p} \gamma^{\prime 2}}{\sigma T_{s}\left(\gamma^{\prime}-\gamma^{\prime \prime}\right)} \frac{1}{\ddot{B}_{L}}(\Delta \theta)^{3} \equiv B(\Delta \theta)^{3}
$$

where

$$
B \equiv \frac{J \lambda c_{p} \gamma^{\prime 2}}{\sigma T_{0}\left(\gamma^{\prime}-\gamma^{\prime \prime}\right)} \frac{1}{B_{L}}
$$

$1 / B_{L}$ : empirical constant evaluated by Levy using experimental data in saturated boiling by Cichelli-Bonilla and others.

To apply Eq. (10) to surface boiling, Levy modified it as follows :

$$
q=B\left(\Delta \theta_{s}\right)^{3} \frac{r+c_{p} \Delta \theta_{\mathrm{sub}}}{r}
$$

However, since Eq. (10) is completely the same as author's Eq. (6), coefficient of heat transfer in surface boiling should be able to be correlated even without Eq. (11), if Eq. (10) is rewritten by substitution of $\Delta \theta_{s}$ for $\Delta \theta$ in it as follows :

$$
q=B\left(\Delta \theta_{s}\right)^{3}
$$

For example, data of $\mathrm{UCLA}^{(2)} \quad(p=2000$ psia $)$ correlated by Eq. (8) are shown in Fig. 13.

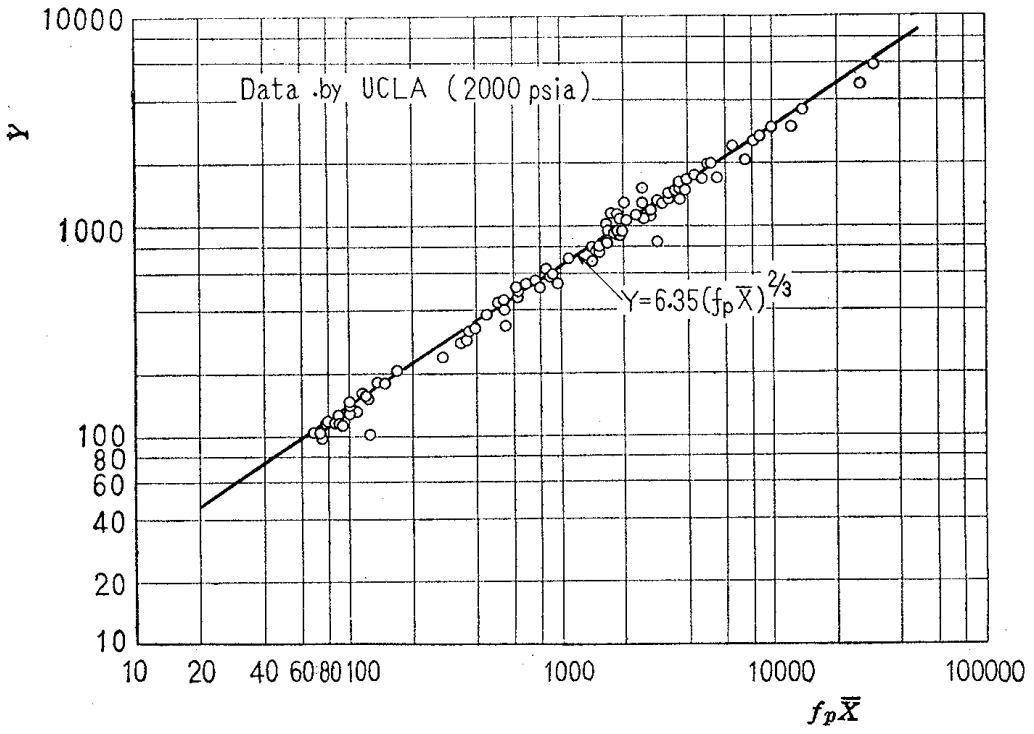

Fig.13 Correlation of data by Buchberg and et al, with $Y$ versus $f_{p} \bar{X}$
In this figure, $f_{p}$ is the pressure factor, i.e., a factor to correct the effect of pressure upon the coefficient of heat transfer ${ }^{(5)}$.

Now, we are going to clarify the physical meaning of $\Delta \theta_{s} / \Delta \theta$ included in Eq. (8). The equation which includes the effective stirring length $H_{e}$ and appears on the way to Eq. (1) is such as follows :

$$
\alpha \propto\left(H_{e} q^{2}\right)^{1 / 3}
$$

Replacing $q$ in Eq. (13) with $q\left(\Delta \theta_{s} / \Delta \theta\right)^{3 / 2}$ as a forementioned, it is rewritten as follows :

$\alpha \propto\left[H_{e}\left(\Delta \theta_{s} / \Delta \theta\right)^{3} q^{2}\right]^{1 / 3}$

Now, if $H_{e s} / H_{e}$ is plotted against $\Delta \theta_{s} / \Delta \theta$ for data of this experiment, the obtained data for different heat fluxes come together along a line as shown in Fig. 14, moreover, in the range of $\Delta \theta_{s}$ l $\Delta \theta \leqq 0.8$, there exists the following relation :

$$
\left(H_{e s} / H_{e}\right) \propto\left(\Delta \theta_{s} / \Delta \theta\right)^{3}
$$

Substituting Eq. (15) into Eq. (14); we obtain $\alpha \propto\left[\begin{array}{ll}H_{e s} & q^{2}\end{array}\right]^{1 / 3}$

After all, according to the relation such as Eqs. (13), (14) and (16), it is concluded that, to use $\Delta \theta_{s}$ instead of $\Delta \theta$ in order to correlate the heat transfer in surface boiling is equivalent to correcting the differeance of effective stirring length of bubbles between saturated boiling and surface boiling by means of $H_{e s}$.

\section{Conclusion}

We carried out an experiment of surface

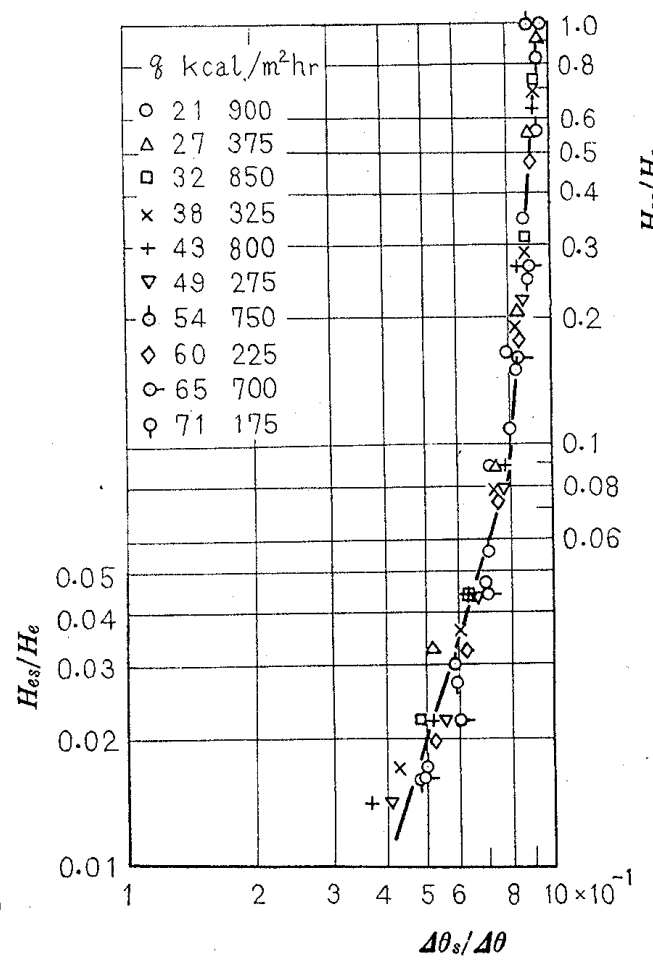

Fig.14 Effective stirring length of bublles related to temperature difference 
boiling of water under free convection using a horizontal heating surface $10 \mathrm{~cm}$ in diameter and found out that there is no difference of behavior of a bubble on the heating surface between surface boiling and saturated boiling and there is an identical relation between condensing height of bubbles and degree of subcooling and, moreover, we proposed a method to evaluate the effective stirring length of bubbles according to their condensing height. According to these conclusions we correlated experimental data with successfull results. Furthermore, we clarified the physical meaning of correlation of experimental data in surface boiling by means of temperature difference between heating surface and saturated liquid.

Finally, we express our hearty thanks not only to Professor Kiyoshi Yamagata of the Kyushu University for the continuous guidance and encouragement he had given us during this study, but also to both Assistant-Professor Kazuma Urakawa of the Tokushima University and Mr. Ryutaro Shimomura of the Kyushu University for their earnest cooperation with us in this experiment.

\section{Principal nomemclature}

$1 / B_{L}:$ Levy's coefficient

$H$ : liquid level above heating surface, $\mathrm{cm}$

$H_{e}$ : effective stirring length of bubbles in saturated boiling, $\mathrm{mm}$

$H_{e s}$ : effective stirring length of bubbles in surface boiling, $\mathrm{mm}$

$J$ : mechanical equivalent of heat, $\mathrm{kg} \mathrm{m} / \mathrm{kcal}$

$M:$ constant $=900, \mathrm{~m}^{-1}$

$P:$ constant $=1.699, \mathrm{kcal} / \mathrm{hr}$

$R:$ radius of heating surface, $\mathrm{m}$

$T_{s}$ : absolute temperature of saturated liquid, ${ }^{\circ} \mathrm{K}$ $c_{p}$ : specific heat of liquid, $\mathrm{kcal} / \mathrm{kg}^{\circ} \mathrm{C}$ $d_{0}$ : diameter of a bubble just leaving the heating surface, $\mathrm{mm}$

$f:$ frequency of bubble formation, $\sec ^{-1}$

$f_{p}:$ pressure factor

$h$ : condensing height of bubble, $\mathrm{mm}$

$n:$ number of vapor columns

$q$ : heat flux of heating surface, $\mathrm{kcal} / \mathrm{m}^{2} \mathrm{hr}$

$r$ : latent heat of evaporation, $\mathrm{kcal} / \mathrm{kg}$

$\alpha$ : coefficient of heat transfer, $\mathrm{kcal} / \mathrm{m}^{2} \mathrm{hr}{ }^{\circ} \mathrm{C}$

$\gamma^{\prime}$ : specific weight of liquid, $\mathrm{kg} / \mathrm{m}^{3}$

$\gamma^{\prime \prime}:$ specific weight of vapor $\mathrm{kg} / \mathrm{m}^{3}$

$\theta_{m}$ : temperature of jacket water, ${ }^{\circ} \mathrm{C}$

$\theta_{s}:$ saturation temperature of liquid, ${ }^{\circ} \mathrm{C}$

$\theta_{w}$ : temperature of liquid, ${ }^{\circ} \mathrm{C}$

$\Delta \theta:$ temperature difference between heating surface and liquid, ${ }^{\circ} \mathrm{C}$

$\Delta \theta_{s}$ : temperature difference between heating surface and saturated liquid, ${ }^{\circ} \mathrm{C}$

$\Delta \theta_{\text {sub }}$ : degree of subcooling of bulk liquid $=\theta_{s}-\theta_{w}$, ${ }^{\circ} \mathrm{C}$

$\lambda$ : thermal conductivity of liquid, $\mathrm{kcal} / \mathrm{m} \mathrm{hr}{ }^{\circ} \mathrm{C}$

$\sigma:$ surface tension of liquid, $\mathrm{kg} / \mathrm{m}$

\section{References}

(1) K. Nishikawa, et al: Trans. Japan Soc. Mech. Engrs., Vol.18, No.72 (1952), p.27.

(2) K. Kreith and M. Summerfield:Trans. ASME, Vol. 71 (1949), p.805; J.A. Clark and W.M. Rohsenow: Trans. ASME, Vol.76 (1954), p.553; H. Buchberg, et al: U.S.AEC, Contract, No.AT-11-1-Gen-9(1951); W.H. MacAdams, et al: Indust, Engng. Chem., Vol.41 (1949), p.1941.

(3) M. Jokob: Mech. Engng., Vol.58, No.10 (1936), p. 643.

(4) K.Yamagata, et al: Trans.Japan Soc.Mech.Engrs., Vo1.17, No.62 (1951), p.163.

(5) K. Nishikawa: Trans, Japan Soc. Mech. Engrs., Vol.22, No.120 (1956), p.557.

(6) W.M. Rohsenow: Lectures at Symposium on Heat Transfer, Univ. of Michigan, (1953), p.101.

(7) S. Levy : Trans. ASME, Ser. C, Vol. 81 , No. 1 (1959), p.37. 